\title{
Lessons in IBD pathogenesis from new animal models of spontaneous colitis
}

\author{
R BALFOUR SARTOR MD
}

\begin{abstract}
RB SARTOR. Lessons in IBD pathogenesis from new animal models of spontaneous colitis. Can J Gastroenterol 1995;9(6):309-315. The recent explosion of transgenic and targeted gene deleted (knockout [KO]) rodents has yielded a number of new animal models of spontaneous, chronic intestinal inflammation that have provided novel insights into the pathogenesis of human inflammatory bowel disease (IBD). Spontaneous colitis resulting from deletion of genes encoding key immunoregulatory cytokines (interleukin [IL]-2, IL-10 and transforming growth factor [TGF]-beta) and T cell receptors (TCRs) demonstrates that an intact mucosal immune response prevents colitis. The TCR KO model incriminates B lymphocytes in spontaneous colonic inflammation - TCR KO with intact B cells causes colitis, but simultaneous deletion of $\mathrm{T}$ and $\mathrm{B}$ cells does not. This model and induction of colitis in severe combined immunodeficient (SCID) mice by constitution with one $\mathrm{T}$ cell subset (CD45RH $\mathrm{R}^{\mathrm{hi}}$ ), but prevention by addition of the CD45RB ${ }^{10}$ subset, strongly suggest that $T$ cell subsets down-regulate inflammation in the normal, immunocompetent host. An essential role for normal luminal bacteria in induction and perpetuation of enterocolitis is provided by the absence of chronic intestinal inflammation in germ-free (sterile) IL-2 KO mice and human leukocyte antigen (HLA)-B27 transgenic rats, and attenuated inflammation in IL-2 and IL-10 KO mice raised under specific pathogen-free conditions. The fundamental role of host genetic susceptibility in chronic intestinal inflammation and systemic manifestations is established by development of spontaneous colitis and perianal inflammation in $\mathrm{C}_{3} \mathrm{H} / \mathrm{HeJ}$ Bir substrain mice and HLA-B27 transgenic rats. (Pour le résumé, voir page 310)
\end{abstract}

Key Words: Animal models, Colitis, Enterocolitis, Gene knockout, Genetic engineering, Transgenic

Center for Gastrointestinal Biology and Disease, University of North Carolina, Chapel Hill, North Carolina, USA

Correspondence: Dr R Balfour Sartor, Division of Digestive Diseases and Nutrition, School of Medicine, Department of Medicine, CB 7080, Room 326 Burnett-Womack Building, University of North Carolina at Chapel Hill, Chapel Hill, NC 27599-7080, USA. Telephone

919-966-0149, fax 919-966-6842, e-mail rbs@med.unc.edu

This paper was presented at the Trends in Inflammatory Bowel Disease Therapy meeting, April 6 to 9, 1994, held in Victoria, British Columbia. This paper has also been published in Sutherland LR, et al, eds. Inflammatory Bowel Disease: Basic Research, Clinical Implications and Trends in Therapy. Boston, Dordrecht and London: Kluwer Academic Publishers, 1994
U NTIL RECENTLY, MOST EXperimental models of intestinal inflammation have been induced in laboratory animals by exposure to a variety of toxins of questionable environmental relevance $(1,2)$ (Table 1$)$. The exception is the cotton-top tamarin, which spontaneously develops colitis and adenocarcinoma of the colon. However, this new world marmoset is on the endangered species list and is not widely available. Existing animal models have provided very important insights into soluble mediators involved in acute and, in some cases, chronic intestinal inflammation. However, the acute injury response to toxins is of limited value to assist the understand-ing of basic immunoregulatory defects relevant to the pathogenesis of idiopathic chronic inflammatory bowel disease (IBD) in humans.

Significant improvements in traditional animal models have been made by exploring the differential genetic susceptibility of inbred rat strains to bacterial cell wall polymers $(1,3)$. Inbred Lewis rats develop a biphasic, spontaneously relapsing granulomatous enterocolitis with associated fibrosis, arthritis, granulomatous hepatitis, anemia and leukocytosis after intramural injection of peptidoglycanpolysaccharide (PG-PS) polymers. The 


\section{La pathogenèse des MII tirée de nouveaux modèles animaux de colite spontanée}

RÉSUMÉ : La récente multiplication de rongeurs transgéniques dont un gène ciblé a été éliminé (knockout [KO]) a donné lieu à un nombre de nouveaux modèles animaux d'inflammation intestinale chronique spontanée qui donnent un éclairage nouveau à la pathogenèse des maladies inflammatoires de l'intestin chez l'humain (MII). La colite spontanée résultant de l'élimination de gènes responsables de l'encodage des cytokines immunorégulatrices clés (interleukine IL-2, IL-10 et facteur de croissance transformant [TGF]-bêta) et les récepteurs des cellules T (TCR) démontrent qu'une réponse immunitaire intacte au niveau de la muqueuse prévient la colite. Le modèle TCR KO élimine les lymphocytes B dans l'inflammation spontanée du côlon. Les TCR KO avec cellules B intactes provoquent la colite, contrairement à l'élimination simultanée des cellules T et B. Ce modèle et l'induction de la colite chez des souris atteintes d'une immunodéficience combinée congénitale grave avec un sous-ensemble de cellules $T$ (CD45RH $\left.{ }^{\text {hi }}\right)$, qui peut être prévenue par l'ajout de la sous-série CD45RB ${ }^{l o}$, suggèrent fortement que les sous-ensembles de cellules $T$ régissent à la baisse l'inflammation chez l'hôte immunocompétent normal. Le rôle central des bactéries normales dans l'induction et la perpétuation de l'entérocolite est rendu possible par l'absence d'inflammation intestinale chronique chez des souris IL-2 KO non contaminées (stériles) et chez des rats transgéniques (HLA)-B27 soumis à l'antigène leucocytaire humain et par l'atténuation de l'inflammation chez des souris IL-2 et IL-10 KO dans des conditions spécifiques, sans organisme pathogène. Le rôle fondamental de la sensibilité génétique de l'hôte dans l'inflammation intestinale chronique et dans les manifestations systémiques a pu être confirmé par l'installation de colite et d'inflammation périanale spontanée chez des sous-espèces de souris $\mathrm{Bir} \mathrm{C}_{3} \mathrm{H} / \mathrm{HeJ}$ et des rats transgéniques HLA-B27.

\section{TABLE 1}

Established animal models of intestinal inflammation

\begin{tabular}{lcc}
\hline Mucosal & Intermediate & Transmural \\
\hline $\begin{array}{l}\text { Dextran sulphate sodium } \\
\text { (mouse) }\end{array}$ & Acetic acid (rat) & $\begin{array}{c}\text { Trinitrobenzene-sulphonic acid } \\
\text { (rat, mouse) }\end{array}$ \\
$\begin{array}{l}\text { Immune complex } \\
\text { (rabbit) }\end{array}$ & $\begin{array}{c}\text { Peptidoglycan-polysaccharide } \\
\text { (rat) }\end{array}$ \\
$\begin{array}{l}\text { Carrageenan (guinea pig) } \\
\text { Cotton-top tamarin }\end{array}$ & Indomethacin (rat, dog) \\
\hline
\end{tabular}

TABLE 2

New rodent models of spontaneous intestinal inflammation

\begin{tabular}{llc}
\hline Spontaneous mutation & Genetically engineered & Reconstituted \\
\hline $\mathrm{C}_{3} \mathrm{H} / \mathrm{HeJ}$ Bir mouse & HLA-B27 $\beta_{2} \mu$ transgenic rat & $\mathrm{CD} 45 \mathrm{RB} \mathrm{B}^{\text {hi }} \rightarrow$ SCID mouse \\
& $\mathrm{LL}-2$ deleted mouse & \\
& $\mathrm{LL}-10$ deleted mouse & \\
& $\alpha \beta$ TCR deleted mouse & \\
& TGF- $\beta_{1}$ deleted mouse & \\
\hline
\end{tabular}

HLA-B27 $\beta_{2} \mu$ Human leukocyte antigen B27 $\beta_{2}$ microglobulin; IL Interleukin; SCID Severe combined immunodeficient; TCR T cell receptor; TGF Transforming growth factor

chronic phase of PG-PS-induced enterocolitis is T lymphocyte-mediated and persists for at least six months. In contrast, Fischer F344 rats (major histocompatibility complex [MHC]-matched with Lewis) and Buffalo rats develop only transient intestinal injury and no extraintestinal inflammation. Although the PG-PS model has several unique features, intramural injection of PG-PS at the time of laparotomy is a tedious and nonphysiological means of inducing experimental and intestinal inflammation.

Recent advances in molecular biological techniques have made it practical to overexpress or delete genes of interest in rodents as well as in viruses, bacteria, yeast and cultured cells. Overexpression (transgenic) and deletion (knockout [KO]) of specific human leukocyte antigen (HLA), cytokine and T cell receptor (TCR) genes in rodents have provided important and sometimes surprising models of spontaneous colitis (Table 2). These new models, in combination with a spontaneous mutation in $\mathrm{C}_{3} \mathrm{H} / \mathrm{HeJ}$ mice, restoration of $\mathrm{T}$ cell subsets to immunocompromised mice and induction of intestinal inflammation by PG-PS, indomethacin or trinitrobenzene-sulphonic acid in inbred rodent strains, have provided novel insights into mechanisms of chronic intestinal and systemic inflammation.

This paper describes clinical, histological and immunological features of these animal models, concentrating on the newer, genetically engineered rodents that spontaneously develop chronic intestinal inflammation. These new rodent models provide the tools to dissect the basic mechanisms of chronic intestinal and systemic inflammation and provide relevant insights into the pathogenesis of IBD.

\section{$\mathrm{C}_{3} \mathrm{H} / \mathrm{HeJ}$ BIR SUBSTRAIN MICE}

In 1994 Sundberg and colleagues (4) described a heritable form of colitis in mice. Over the past 10 years it became apparent that individual $\mathrm{C}_{3} \mathrm{H} / \mathrm{HeJ}$ mice episodically developed diarrhea and perianal ulceration with no demonstrable pathogens. Selective breeding of mice exhibiting diarrhea established a pedigree in which there is a $50 \%$ incidence of spontaneous colitis. There is a male predominance $(67 \%$ incidence in males, $31 \%$ in females) and seasonal variation (occurring more often in winter than in summer). The time course of inflammation is biphasic. The most reproducible inflammation develops at three to five weeks of age with spontaneous resolution in most mice. Some mice exhibit chronic inflammation, which is failure to re- 
solve either the acute phase or spontaneous reactivation of chronic inflammation. Clinical manifestations of inflammation include occasional diarrhea, hemoccult-positive stools and perianal ulceration. Inflammation is routinely found in the cecum near the ileocecal valve, but can involve the left colon. Histological characteristics include focal linear ulcers with infiltration of mononuclear cells and neutrophils. Extraintestinal manifestations have not yet been reported.

The mechanism(s) of spontaneous colitis in the $\mathrm{C}_{3} \mathrm{H} / \mathrm{HeJ}$ Bir substrain mouse have not yet been determined. Presumably the propensity to develop inflammation is the result of spontaneous mutation of a specific gene. Attempts to identify this gene are in progress, and if successful will provide important clues to direct investigations of specific gene mutations in IBD patients. The $\mathrm{C}_{3} \mathrm{H} / \mathrm{HeJ}$ parent strain is interesting because it is resistant to bacterial lipopolysaccharide (LPS) or endotoxin. Like the parent strain, macrophages from $\mathrm{C}_{3} \mathrm{H} / \mathrm{HeJ}$ Bir mice fail to produce interleukin (IL)- 1 or tumour necrosis factor (TNF)-alpha in response to in vitro LPS stimulation (5).

\section{HLA-B27 TRANSGENIC RATS}

HLA-B27/ $\beta_{2}$ microglobulin $\left(\beta_{2} \mu\right)$ transgenic rodents were developed to determine whether experimental in vivo expression of this class I MHC molecule would drive a systemic inflammatory response that resembles the human HLA-B27 syndrome. HLAB27/ $\beta_{2} \mu$ transgenic mice fail to exhibit clinical evidence of spontaneous inflammation, but are more susceptible to experimental infection with Yersinia species (6). However, transgenic rats that expressed high copy numbers of the human HLA-B27/ $\beta_{2} \mu$ gene develop a systemic syndrome of polyarthritis, dermatitis, hair loss, nail changes, myocarditis, epididymitis, progressive wasting, gastritis and colitis (7). Surprisingly, diarrhea usually precedes other manifestations and is clinically evident in $50 \%$ of transgenic rats by 10 weeks of age and in almost $100 \%$ by 20 weeks of age (8). The chronic diarrhea is not grossly bloody and is associated with in- termittent perianal ulceration (unpublished observations). The colon is grossly thickened and granular but has no discrete ulceration, nodularity or strictures. Histologically there is an infiltration by mononuclear cells into the lamina propria, with occasional crypt abscesses in severe cases. Inflammation is confined to the mucosa in almost all rats. Crypts are hyperplastic with reactive atypia and goblet cell depletion. The majority of rats exhibit focal areas of gastric inflammation in the lamina propria and submucosa with a proliferation of mucus-neck cells and grandular ectasia. In the joints, neutrophils accumulate in the joint space; the synovium is hyperplastic, infiltrated with mononuclear cells, and pannus erodes the bone.

Several studies have been performed to determine the mechanisms of progressive intestinal and systemic inflammation in this model. The susceptibility to inflammation correlated with the level of human HLA-B27/ $\beta_{2} \mu$ expression on lymphoid cells (8). Eighty per cent of hemizygous transgenic rats in two lines that express more than 50 copies of recombinant HLA-B27/ $\beta 2 \mu$ per cell developed clinically evident colitis and systemic disease by 10 to 16 weeks of age. Rats from lines expressing low copy numbers of B27 failed to develop inflammation even in the homozygous state, whereas homozygous but not heterozygous offspring of mid-level line developed clinical disease. Interestingly, there is no apparent difference in frequency or onset of colitis or systemic inflammation in Lewis or Fischer rat lines that express equivalent copy numbers of the transgene. The lack of clinically apparent spontaneous inflammation in transgenic mice expressing high copy numbers of the same construct is difficult to explain.

Clinical disease can be transferred by bone marrow cells from HLA-B27-positive donors to irradiated B27-negative recipients (9). Disease can also be transferred by fetal liver cells, but not by mature lymph node or spleen cells, indicating that repopulation of the recipient by B27-positive progenitor cells is necessary for disease initiation and that donor cells do not need to be derived from rats with active inflammation. Moreover, disease remitted in B27-positive, irradiated recipients following engraftment with B27-negative cells. These studies demonstrate the colitis is mediated by immunocytes and that HLA-B27 expression by nonimmune cells (epithelial, endothelial, etc) is neither sufficient nor necessary for colitis induction.

Several studies demonstrate a fundamental role of ubiquitous conventional flora in the pathogenesis of HLA-B27 associated colitis and arthritis $(10,11)$. HLA-B27/ $\beta_{2} \mu$ transgenic rats raised in a sterile (germ-free) environment fail to develop clinically apparent diarrhea or arthritis and have no elevation of colonic myeloperoxidase or IL-1 compared with rats housed under conventional conditions with no demonstrable bacterial pathogens. The incidence of arthritis in HLA-B27 transgenic rats repopulated with specific pathogen-free bacterial flora is less than in those raised in a conventional rodent facility. Despite the absence of colitis and arthritis, germ-free transgenic rats develop hair loss, dermatitis and epididymitis to the same degree as conventional B27-positive rats. A role for anaerobic bacteria is suggested by attenuation of colitis and gastritis by metronidazole (12).

\section{IL-2 KO MICE}

IL-2 is a key immunoregulatory cytokine produced by activated $\mathrm{T}$ helper $(\mathrm{TH})_{1}$ lymphocytes whose principal activities are to stimulate proliferation and activation of effector and regulatory lymphocytes (13). Mice homozygous for the mutated IL-2 gene (IL-2-/-) develop normally for three to four weeks before exhibiting a progressive wasting syndrome (14). Approximately $50 \%$ of mice die by nine weeks of age with evidence of splenomegaly, lymphadenopathy and severe hemolytic anemia. Surviving mice develop chronic diarrhea, episodic bloody stools and rectal prolapse, which become clinically evident between six and 15 weeks of age. Progressive disease results in death by 10 to 25 weeks. These mice develop pancolitis, with 
TABLE 3

Pathogenesis of colitis in $\alpha \beta$ TCR deficient mice

\begin{tabular}{lccc}
\hline Strain & CD4 $4 \alpha \beta$ T cells & B cells & Colitis \\
\hline Wild type & + & + & No \\
TCR $\delta$ KO & + & + & No \\
Nude & - & + & NO \\
RAG-1 KO & - & - & No \\
TCR $\alpha$ KO & - & + & Yes \\
TCR $\beta$ KO & - & + & Yes \\
TCR $\beta$ KO X $\delta$ KO & - & + & Yes \\
Class II MHC KO & - & + & Yes
\end{tabular}

KO Knock out; MHC Major histocompatibility complex; RAG Recombination-activating gene; TCR T cell receptor

the left colon affected to a greater degree, but no evidence of small intestinal inflammation. The inflamed colon is thickened with crypt hyperplasia but inflammation is confined to the mucosa. The mucosa is ulcerated, crypt abscesses are present and the lamina propria is infiltrated by mononuclear cells and neutrophils. In advanced stages, epithelial dysplasia is noted. Amyloidosis develops in the liver, spleen and kidney.

Immunopathogenesis of colitis in this model has been explored by immunohistochemical staining. The number of $\mathrm{T}$ and $\mathrm{B}$ cells within the lamina propria dramatically increases in colitic mice which had up to 100 times more $\mathrm{T}$ lymphocytes than controls. In the late stages of disease, colonic B cells are reduced. $\mathrm{T}$ lymphocytes in inflamed colons are activated, as indicated by the CD44 (activated memory T cells) and CD69 (early $\mathrm{T}$ cell activation) markers. $\mathrm{T}$ cells within inflammatory foci have increased proliferation rates. Lamina propria immunoglobulin (Ig) G1 and IgA secreting cells are dramatically increased and serum IgA is elevated 16 to 64 times the control values. Anticolon antibodies are increased until late stages of inflammation, but are part of a generalized autoantibody response.

Bacterial and viral pathogens were not detected and there was no evidence of horizontal disease transmission in normal litter mates. However, normal luminal bacteria were implicated by no clinical or histological evidence of colitis in three IL-2 deficient germ-free mice followed for five months in a sterile environment. KO mice raised under specific pathogen-free conditions developed no clinical signs of colitis, but had evidence of mild histological and immunological abnormalities by 17 to 20 weeks of age.

\section{IL-10 DEFICIENT MICE}

IL-10, a product of $\mathrm{TH}_{2}$ lymphocytes, is believed to have predominantly immunosuppressive activity by virtue of natural killer cells, lymphocyte activation and cytokine production (13). IL10 deficient mice spontaneously develop chronic inflammation of their entire intestinal tract, with the most severe inflammation in the duodenum, proximal jejunum and right colon (15). These mice develop a progressive wasting syndrome with anemia which begins by three to four weeks of age and results in 30\% mortality by five to six weeks. Male and female mice are equally affected. The proximal small bowel is markedly thickened due to mucosal and crypt hyperplasia. The crypt architecture is deranged and dysplastic with a decrease in Peyer's patches. Superficial erosions are present with exudate. Away from ulcerated areas the lamina propria is infiltrated by mononuclear cells, neutrophils and occasional multinucleated giant cells. Inflammation diminishes in the distal small bowel, with atrophy of the ileal mucosa. Colonic lesions are predominantly atrophic. Liver histology is normal but the bone marrow demonstrates an increased myeloid: erythroid ratio.

The majority of plasma cells in inflamed intestine produced IgA or IgG1, and expression of MHC class II moleits ability to downregulate macrophage cules was increased on small intestinal and colonic epithelial cells. Serum $\operatorname{IgG} 1$ and $\operatorname{Ig} \mathrm{A}$ levels were increased in IL-10 -/- mice. The antibody response to immunization with a $\mathrm{T}$ celldependent antigen was similar in IL-10 deleted and control mice. However, in vivo nippostrongylus infection stimulated a $\mathrm{TH}_{1}$ (increase in interferon [IFN]-gamma) lymphokine response in IL-10 - - - mice versus the usual TH2 (IL-4, IL-5) response in controls. Interestingly, spleen cells from the $\mathrm{KO}$ mice produced 20 -fold more IL- 6 and TNF- $\alpha$ than normal mice following LPS stimulation. These results suggest that deficient production of IL-10, which suppresses activation and cytokine synthesis by macrophages, natural killer cells and $\mathrm{T}$ cells, could lead to chronic stimulation by luminal bacterial components. This hypothesis is supported by the observation that IL-10 deficient mice reared under specific pathogen-free conditions have only isolated left-sided colitis with no histological evidence of small intestinal inflammation.

\section{$\alpha \beta$ TCR DEFICIENT MICE}

The TCR is a heterodimer comprising either $\alpha+\beta$ or $\gamma+\delta$ subunits. Antigen binding to the TCR complex in conjunction with accessory ligand binding and costimulatory cytokines is required for antigen-specific activation of $T$ lymphocytes. Mutation of various components of the TCR has been elegantly studied by Mombaerts et al (16). Deletion of the $\alpha$ or $\beta$ chains of the TCR in mice induces spontaneous colitis, with onset by three to four months of age and mortality by six to 12 months. Mice develop nonbloody diarrhea, weight loss and rectal prolapse due to a pancolitis which affects the left side more than the right side. The colon is quite thickened due to massive crypt hyperplasia, goblet cell depletion, acute and chronic inflammation of the lamina propria and crypt abscesses. Macroscopic mucosal ulcerations and rectal bleeding are not seen. The small intestine is grossly and histologically normal, but mesenteric lymph nodes are enlarged and focal hepatic inflam- 
matory cell infiltrates are present in some mice.

The authors examined multiple deletion constructs to investigate mechanisms of immunodeficiency leading to colitis in this model (Table 3 ). The common denominator in mice that developed colitis is the absence of $\alpha \beta$ $\mathrm{T}$ lymphocytes and the presence of functional B cells. An important clue is the lack of colitis in mice with mutated recombination-activating genes (RAG-1) and in severe combined immunodeficient (SCID) mice, which are totally deficient in mature $\mathrm{T}$ and $\mathrm{B}$ lymphocytes. These results suggest that spontaneous colitis in this model is the result of lack of appropriate $\alpha \beta \mathrm{T}$ cellmediated suppression of B cells. Analysis of the $\alpha \beta$ TCR mutation in several inbred mouse strains demonstrated that $129 / \mathrm{Sv}$ and $\mathrm{C}_{3} \mathrm{H} / \mathrm{He}$ were permissive and Balb/c were more resistant.

\section{LYMPHOCYTES SUBSET RECONSTITUTED

IMMUNODEFICIENT MICE

The SCID mouse and nude rat can be populated with immunocytes without rejection, which permits the in vitro study of the activity of various $T$ cell subpopulations. Based on studies by Powrie and Mason (17) in nude rats, several groups have described colitis resulting from injection of $\mathrm{T}$ lymphocyte subsets divided on the basis of binding density of the monoclonal antibody CD45RB into SCID mice $(18,19)$. $\mathrm{CD}_{45 \mathrm{RB}}{ }^{\text {hi }}$ lymphocytes have been shown to secrete profiles of $\mathrm{TH}_{1}$ lymphokines whereas CD45 ${ }^{\text {lo }}$ cells secrete $\mathrm{TH}_{2}$ lymphokines. Injection of unfractionated cells or combined CD45RB ${ }^{\text {hi }}$

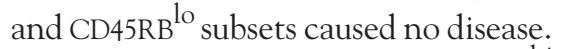
However, injection of only CD45RB ${ }^{\text {hi }}$ lymphocytes induced chronic wasting beginning 10 to 30 days after reconstitution with $30 \%$ mortality at 12 weeks. Intestinal inflammation is predominantly in the colon (left side more affected than right side) but was mild in the small intestine. Histological examination of the small intestine revealed focal mononuclear infiltrates in the lamina propria. Colon inflammation was characterized by focal ulceration, chronically thickened mucosa with

TABLE 4

Immunological mechanisms of spontaneous colitis in genetically engineered rodents

Defective T cell suppression: CD45RB ${ }^{\text {hi }} \rightarrow$ SCID, $\alpha \beta T C R-/-$, TGF- $\beta 1-/-$

$\uparrow \mathrm{TH}_{1} / \mathrm{TH}_{2}$ lymphokines: IL-10 -/-, CD45RB ${ }^{\mathrm{hi}} \rightarrow \mathrm{SCID}$

$\uparrow \mathrm{B}$ cell response: IL-2 -/-, $\alpha \beta \mathrm{TCR}-/-$

IL Interleukin; SCID Severe combined immunodeficient; TCR T cell receptor; TGF Transforming growth factor; TH T helper

crypt hyperplasia and a mononuclear cell infiltrate of the lamina propria with occasional neutrophils and transmural inflammation. Mild periportal infiltrates were seen in the liver.

IFN $-\gamma$ mRNA tissue concentrations were substantially higher than normal values in SCID mice reconstituted with CD45RB ${ }^{\text {hi }}$ cells, but IL-10 levels were not increased (19). IL-4 levels were undetectable in all mice, and TNF- $\alpha$ was elevated in reconstituted mice with and without colitis. These results indicate that $\mathrm{CD} 45^{\text {lo }}$ lymphocytes can suppress intestinal inflammation, which is mediated by the reciprocal CD $45^{\text {hi }}$ population, and suggest that a disregulation between $\mathrm{TH}_{1}$ and $\mathrm{TH}_{2}$ lymphokine production may contribute to chronic intestinal inflammation. These studies graphically illustrate the essential role of competent immunosuppressive cells in homeostasis of the intestinal mucosa.

\section{TRANSFORMING GROWTH FACTOR-BETA DEFICIENT MICE}

Transforming growth factor (TGF)-beta is a macrophage product that has pleiotropic immunological activities including monocyte chemotaxis and stimulation of collagen synthesis by intestinal smooth muscle cells and fibroblasts (13). An important immunoregulatory activity of this molecule is suppression of lymphocyte proliferation. TGF- $\beta_{1} \mathrm{KO}$ mice have increased in utero mortality, but appear to develop normally until weaning (three weeks of age), when they develop a wasting syndrome and systemic inflammation consisting of myocarditis, bronchoalveolar inflammation, pancreatitis and dermatitis $(20,21)$. One of the two reported TGF- $\beta_{1}$ deficient lines develops diarrhea and has incompletely described colitis (20). The mechanisms of chronic systemic inflammation and colitis in this model remain obscure, but may be related to defective suppression of lymphocytes. Of interest, many of the organs involved are colonized by ubiquitous bacteria.

\section{SUMMARY AND CONCLUSIONS}

Chronic intestinal inflammation that develops in response to spontaneous gene mutations, targeted deletion or overexpression of specific genes or selective manipulation of lymphocytes subsets can provide important insights into the mechanisms of intestinal inflammation (22). Several broad immunological mechanisms that mediate spontaneous colitis are listed in Table 4. The similarities of chronic intestinal inflammation in these models to idiopathic ulcerative colitis and Crohn's disease suggest that similar mechanisms may be active in human IBD.

A theme common to many of these models is that intestinal inflammation develops as a result of defective immunosuppression. Models of TGF- $\beta_{1}$ KO, $\alpha \beta$ TCR deletion and CD45RB hi reconstitution of SCID mice clearly demonstrate the consequences of ineffective $\mathrm{T}$ lymphocyte suppression and suggest that $T$ cell suppression is critical to normal mucosal homeostasis. The disordered balance between $\mathrm{TH}_{1}$ and $\mathrm{TH}_{2}$ lymphokine profiles in IL-10 $\mathrm{KO}$ and $\mathrm{CD} 45 \mathrm{RB}^{\mathrm{hi}} \rightarrow$ SCID mice further documents the importance of effective immunoregulation by lymphocytes. How these animal studies relate to the proposed TH1 profile of Crohn's disease and $\mathrm{TH}_{2}$ for ulcerative colitis remains to be determined, but it is of interest that IL-10 -/- and reconstituted SCID mice have small intestinal inflammation and $\mathrm{TH}_{1}$ lymphokine profiles. Evidence from TCR deletion studies and IL-2 KO mice strongly suggest that in the absence of regulatory $\mathrm{T}$ cells, uncon- 
trolled B lymphocyte activation is capable of mediating mucosal damage.

A second concept is that specific gene mutations can cause spontaneous intestinal inflammation and that clinically and histologically similar lesions can arise from different immunoregulatory defects. These observations illustrate the limited repertoire of mechanisms of tissue injury, suggest that a variety of immunoregulatory defects may induce human IBD and imply that there may be multiple etiologies for these disorders. Moreover, the etiological heterogeneity among ulcerative colitis and Crohn's disease patients may be responsible for clinical subsets of patients with predictable patterns of disease, complications and response to medications.

A third concept is that host genetic susceptibility determines aggressiveness, chronicity and complications of intestinal inflammation. The effect of genetic susceptibility is illustrated by the $\mathrm{C}_{3} \mathrm{H} / \mathrm{HeJ}$ Bir mouse and differential responses to experimental intestinal inflammation in Lewis versus Fischer rats in the PG-PS and indomethacin models $(3,23)$, and $\mathrm{C}_{3} \mathrm{H} / \mathrm{He}$ or $129 / \mathrm{Sv}$ versus Balb/c mice in the $\alpha \beta$ TCR KO model (16). Identification of genetic mechanisms of defective immunoregulation in susceptible rodents could direct the search for genetic susceptibility factors in IBD patients.

Fourth, transfer studies in HLA$B 27 / \beta_{2} \mu$ transgenic rats demonstrate that bone marrow-derived cells can mediate chronic intestinal and sys-

\section{REFERENCES}

1. Sartor RB. Animal models of intestinal inflammation: Relevance to IBD. In: MacDermott RP, Stenson W, eds. Inflammatory Bowel Disease. New York: Elsevier, 1991:337-54.

2. Stenson WF. Animal models of inflammatory bowel disease. In: Targan SR, ed. Inflammatory Bowel Disease from Bench to Bedside. Baltimore: Williams \& Wilkins, 1992:180-92.

3. McCall RD, Haskill S, Zimmerman E, et al. Tissue IL-1 and IL-1 receptor antagonist expression in enterocolitis in resistant and susceptible rats. Gastroenterology 1994;106:960-72.

4. Sundberg JP, Elson CO, Bedigian H, et al. Spontaneous, heritable colitis in temic inflammation. The inflammatory response of these cells is genetically programmed because progenitor cells can be derived from fetuses that do not exhibit evidence of intestinal or systemic inflammation. Moreover, display of HLA-B27 on host epithelial cells is not sufficient for disease induction. This observation suggests that increased expression of MHC molecules during experimental or idiopathic inflammation is a consequence of the inflammatory reaction and is not necessary for chronic intestinal inflammation. Resolution of spontaneous intestinal inflammation in HLA-B27 rats after irradiation and successful bone marrow engraftment from nontransgenic rats raise the possibility of therapeutic bone marrow transplantation in IBD patients.

Finally, attenuation of spontaneous intestinal inflammation in IL-2 and IL10 deficient mice raised in a pathogenfree environment and lack of evidence of colitis in IL-2 KO mice and HLA$B 27 / \beta_{2} \mu$ mice living in germ-free (sterile) conditions dramatically illustrate the critical pathogenetic role of ubiquitous luminal bacterial constituents. These results parallel those observed in indomethacin-induced enterocolitis where gnotobiotic Lewis rats populated with specific pathogen-free flora develop chronic mid-small bowel ulcers but germ-free littermates have no evidence of chronic inflammation (24). Because microbiological conditions vary between each rodent facility, direct comparisons of the clinical features of each spontaneous colitis model

a new substrain of $\mathrm{C}_{3} \mathrm{H} / \mathrm{HeJ}$ mice. Gastroenterology 1994;107:1726-35.

5. McCabe RP, Mills T, Ridwan B, et al. Immune reactivity of $\mathrm{C}_{3} \mathrm{H} / \mathrm{HeJ}$ mice with spontaneous colitis.

Gastroenterology 1993;104:A656.

6. Nickerson CI, Luthra HS, David CS. Role of enterobacteria and HLA-B27 in spondyloarthropathics: Studies with transgenic mice. Ann Rheum Dis 1990;49:426-33.

7. Hammer RE, Maika SD, Richardson JA, Tang J, Taurog JD. Spontaneous inflammatory disease in transgenic rats expressing HLA-B27 and human $\beta_{2} \mu$ : An animal model of HLA-B27associated human disorders. Cell 1990;63:1099-112. must be made under similar conditions, optimally using animals colonized with the same flora. It is unknown whether spontaneous colitis develops as the result of luminal bacteria invading tissues of immunocompromised hosts (IL-2 and TCR KO mice), as a hyperactive response to bacterial components (LPS, PG-PS) in rodents that lack effective immunosuppressor cytokines (IL-10, TGF- $\beta$ KO mice) or as an exaggerated antibody response to ubiquitous bacterial antigens (IL-2, TCR KO models and $\mathrm{CD} 45^{\mathrm{hi}} \rightarrow$ SCID mice).

These genetically engineered rodent models have only recently been described so their usefulness has been only superficially exploited. Similar types of spontaneous intestinal inflammation will almost certainly be discovered as new $\mathrm{KO}$ and transgenic rodents are generated to study other immunoregulatory molecules. Application of sophisticated molecular and immunological techniques and further genetic manipulation by selective crossbreeding with well characterized mouse strains should generate important insights and new enthusiasm to explore mechanisms of chronic intestinal inflammation.

ACKNOWLEDGEMENTS: This work was supported by United States Public Health Service grants DK 40249, DK 47700 and DK 34987 and the Crohn's and Colitis Foundation of America. The author gratefully acknowledges the expert secretarial assistance of Robert Tuttle and Shirley Willard.

8. Taurog JD, Maika SD, Simmons WA, Breban M, Hammer RE. Susceptibility to inflammatory disease in HLA-B27 transgenic rat lines correlates with the level of B27 expression. J Immunol 1993; 150:4186.

9. Breban M, Hammer RE, Richardson JA, Taurog JD. Transfer of the inflammatory disease of HLA-B27 transgenic rats by bone marrow engraftment. J Exp Med 1993;178:1607-16.

10. Taurog JD, Richardson JA, Croft JT, et al. The germfree state prevents development of gut and joint inflammatory disease in HLA-B27 transgenic rats. J Exp Med 1994;180:2359-64. 
11. Rath HC, Bender DE, Grenther T, et al. Normal bacteria stimulate colonic, gastric and systemic inflammation in HLA-B27/ $\beta_{2} \mu$ transgenic rats. Gastroenterology 1995;108:A899. (Abst)

12. Rath HC, Bender DE, Holt LC, et al. Metronidazole attenuates colitis in HLA - B $27 / \beta_{2} \mu$ trangenic (TG) rats: A pathogenic role for anaerobic bacteria. Clin Immunol Immunopathol 1995; 76:545.

13. Sartor RB. Viewpoints on digestive diseases. Cytokines in intestinal inflammation: Pathophysiological and clinical considerations. Gastroenterology 1994;106:533-9.

14. Sadlack B, Merg H, Schorle H, et al. Ulcerative colitis-like disease in mice with a disrupted interleukin-2 gene. Cell 1993;75:253-61.

15. Kuhn R, Lohler J, Rennick D, Rajowsky K, Muller W. Interleukin10-deficient mice develop chronic enterocolitis. Cell 1993;75:263-79.

16. Mombaerts P, Mizoguchi E, Grusby M, et al. Spontaneous development of inflammatory bowel disease in $\mathrm{T}$ cell receptor mutant mice. Cell 1993;75:275-82.

17. Powrie F, Mason D. Ox-22 high CD4+ T cells induce wasting disease with multiple organ pathology: Prevention by the Ox-22 ${ }^{\text {low }}$ subset. J Exp Med 1990;172:1701-8.

18. Morrisey PJ, Charrier K, Braddy S, Liggitt D, Watson JD. CD4+ $\mathrm{T}$ cells that express high levels of CD45RB induce wasting disease when transferred into cogenic severe combined immunodeficient mice. Disease development is prevented by cotransfer of purified CD4+ T cells. J Exp Med 1993;178:237-44.

19. Powrie F, Leach MW, Mauze S, Caddle LB, Coffman RL. Phenotypically distinct subsets of CD4+ T cells induce or protect from chronic intestinal inflammation in C B-17 SCID mice. Int Immunol 1993;5:1461-71.

20. Kulkarni AB, Huh CG, Becker D, et al. Transforming growth factor $\beta 1$ null mutation in mice causes excessive inflammatory response and early death. Proc Natl Acad Sci USA 1993;90:770-4.

21. Shull MM, Ormsby I, Kier AB, et al. Targeted disruption of the mouse transforming growth factor- $\beta 1$ gene results in multifocal inflammatory disease. Nature 1992;359:693-9.

22. Strober W, Ehrhardt RO. Chronic intestinal inflammation: An unexpected outcome in cytokine or T cell receptor mutant mice. Cell 1993;75:203-5.

23. Sartor RB, Bender DE, Holt LC. Susceptibility of inbred rat strains to intestinal and extraintestinal inflammation induced by indomethacin. Gastroenterology 1992;102:A690.

24. Sartor RB, Bender DE, Grenther T, Holt LC. Absolute requirement for ubiquitous luminal bacteria in the pathogenesis of chronic intestinal inflammation. Gastroenterology 1994;106:A767. 


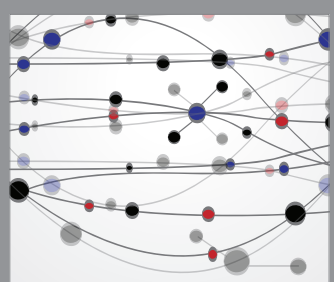

The Scientific World Journal
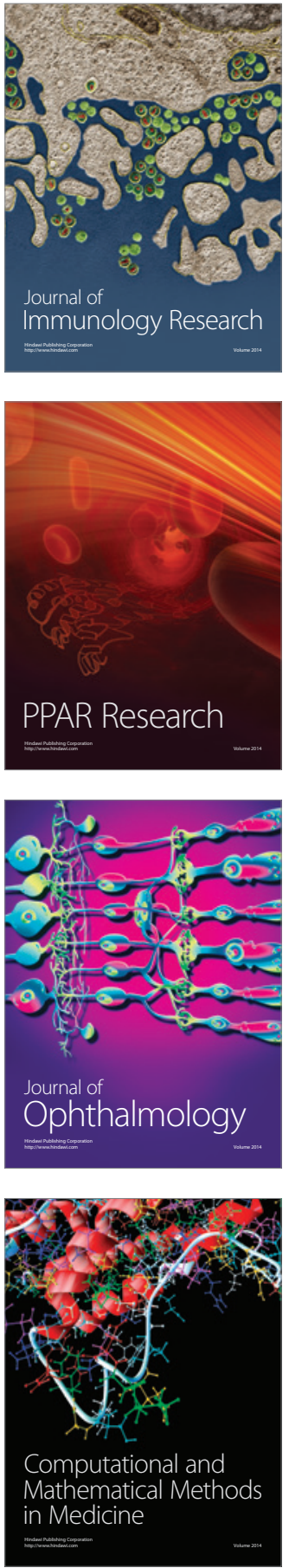

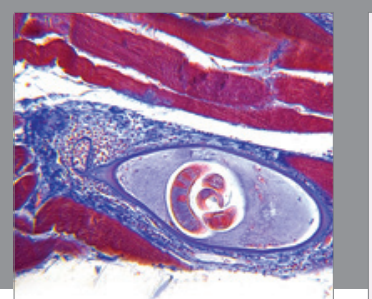

Gastroenterology Research and Practice

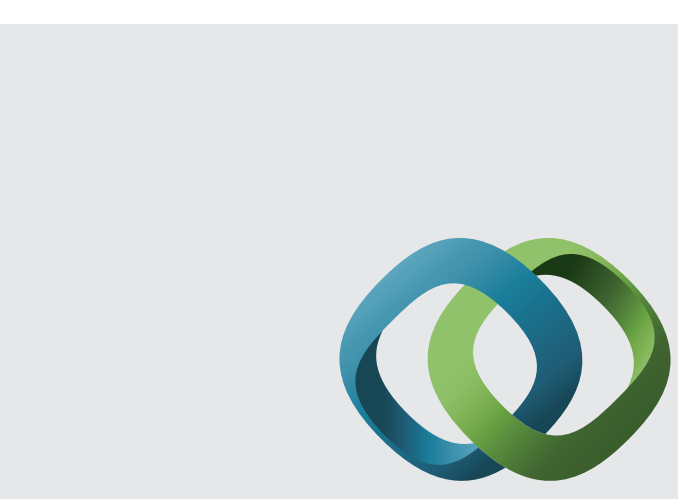

\section{Hindawi}

Submit your manuscripts at

http://www.hindawi.com
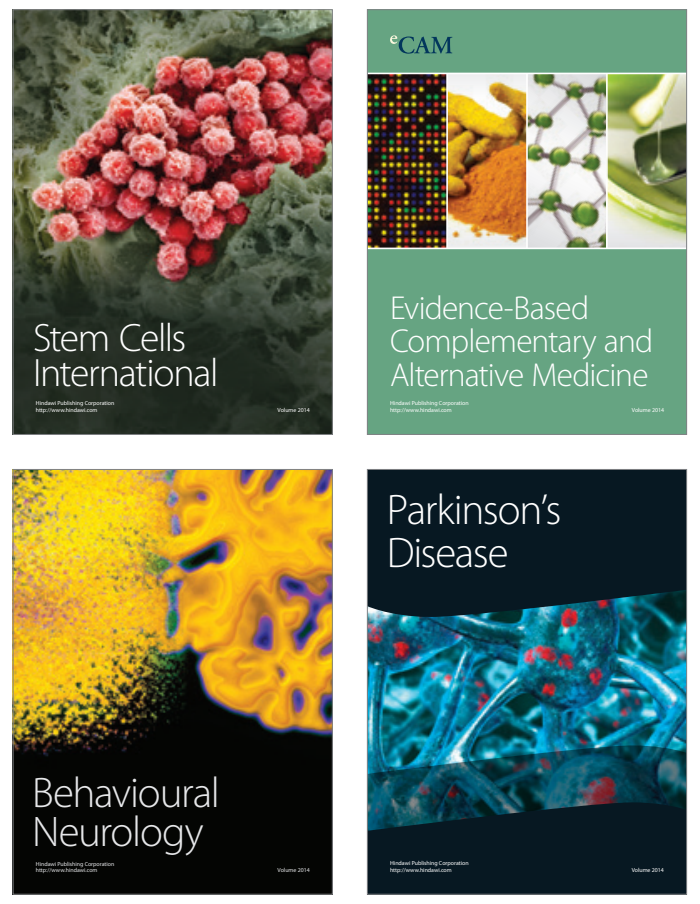
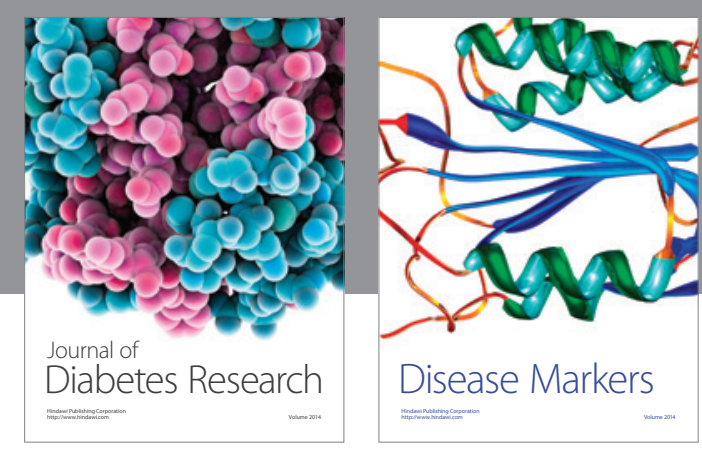

Disease Markers
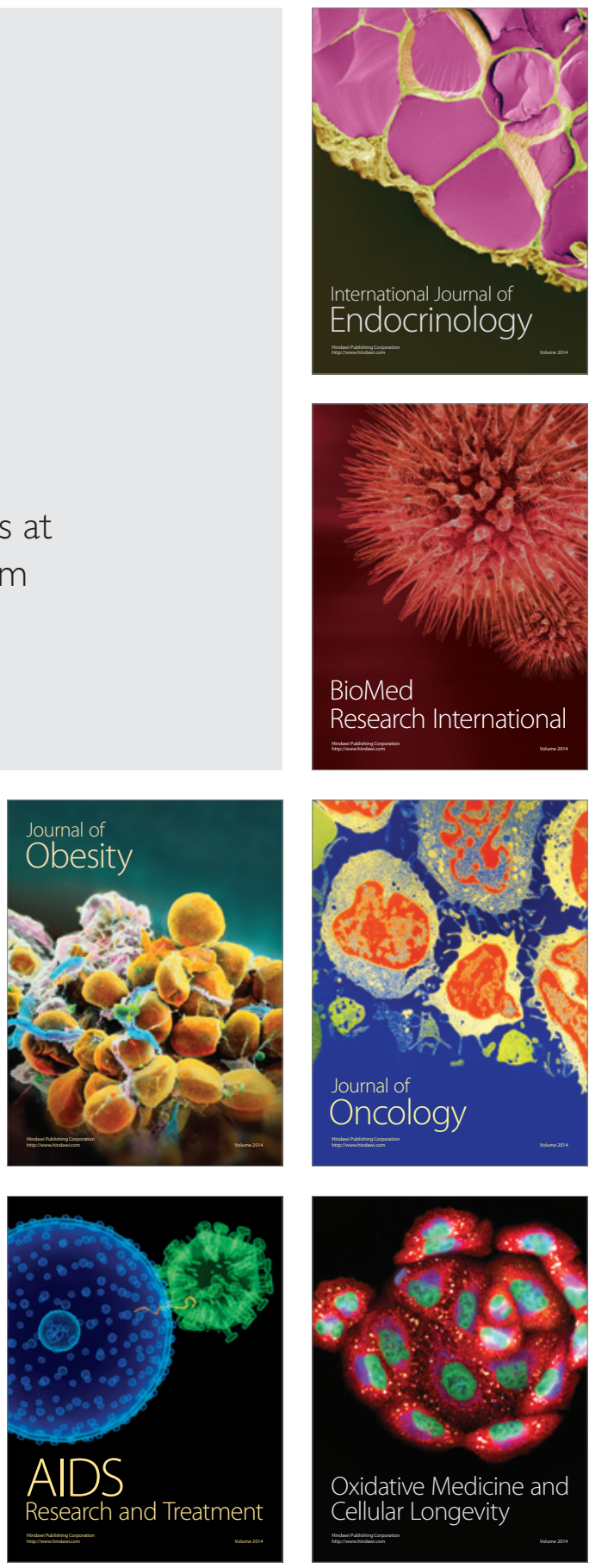